РАЗВИТИЕ ОБЩЕСТВА В УСЛОВИЯХ ТЕХНОЛОГИЧЕСКОЙ РЕВОЛЮЦИИ

\title{
THE DEVELOPMENT OF SOCIETY IN THE CONTEXT OF THE TECHNOLOGICAL REVOLUTION
}

\author{
${ }^{1}$ Усамов И.Р., ${ }^{2}$ Магазиева З.А., ${ }^{3}$ Гастамиров У.А. \\ ${ }^{1}$ UsamovI.R., ${ }^{2}$ Magazieva Z.A., ${ }^{3}$ Gastamirov U A \\ ${ }^{1}$ Старший преподаватель кафедры «Информационные технологии» ГГНТУ им. акад. М.Д. \\ Миллионщикова, г. Грозный, Россия \\ ${ }^{2}$ Ассистент кафедры «Информационные технологии» ГГНТУ им. акад. М.Д. Миллионщикова, \\ г. Грозный, Россия \\ ${ }^{3}$ Студент по направлению «Информационные системы и технологии» ГГНТУ им. акад. М.Д. \\ Миллионщикова, г. Грозный, Россия \\ ${ }^{1}$ Senior Lecturer of the Department of Information Technologies, GSTOU named after acad. M.D. \\ Millionshchikov, Grozny, Russia \\ ${ }^{2}$ Assistant at the Department of Information Technologies, GSTOU named after acad. M.D. \\ Millionshchikov, Grozny, Russia \\ 3Student in the direction "Information systems and technologies" GSTOU named after acad. M.D. \\ Millionshchikov, Grozny, Russia
}

\begin{abstract}
Аннотация. Человечество испытывает на себе прочесс технологической револючии. Многие современные ученные и исследователи едины во мнении о том, что в настоящее время произошло значительное увеличение осадка технологической револючии. Сегодня во все сферы деятельности внедряются современные информащионные технологии. Если еще 10 лет назад нельзя было представить некоторые технологические процессы, то сегодня - это обычное дело. Прочесс развития общества в условиях технологической революиии охватывает процесс влиянии науки и техники на образование, сельское хозяйство, на окружаюшую среду, на коммуникачию, на здоровье и гигиену, на инфраструктуру, на правительство и его планирование. В статье рассматриваются отечественные и зарубежные источники по технологической револючии и влиянию этого прочесса на развитие общества. Сегодня человечество испытывает пик технологической революиии.

Abstract. Humanity is experiencing the process of technological revolution. Many modern scientists and researchers agree that there has been a significant increase in the precipitation of the technological revolution. Today, modern information technologies are being introduced into all spheres of activity. If 10 years ago it was impossible to imagine some technological processes, today it is a common thing. The process of development of society in the context of the technological revolution covers the impact of science and technology on education, agriculture, the environment, communication, health and hygiene, infrastructure, government and its planning. The article examines domestic and foreign sources on the technological revolution and the impact of this process on the development of society. Today, humanity is experiencing the peak of the technological revolution.
\end{abstract}

Ключевые слова: технологическая револючия, развитие общества, технический прогресс, информационное общество.

Keywords: technological revolution, development of society, technical progress, information society.

В наше время огромное влияние на общественное подсознание играет наука и техника. Технический прогресс оказывает большое влияние на общественное социальное взаимодействие. Современные технологии оказывают огромное воздействие на социальную коммуникацию самых разных категорий хозяйств. Технологии дали новые условия коммуникации, которые дали возможность быстро идентифицироваться и обмениваться информацией во всей вселенной. Техника и наука играют роль связующего моста между социальным развитием всех 
категорий граждан, начиная городским населением и заканчивая сельскими поселениями. Технологическая революция, которую мы сейчас испытываем, преобразовала человечество каменного века в современное постиндустриальное общество (информационное общество), которое перешло от физических действий к умственным духовным действиям. Наука и технологии повлияли не только на способ общения, ну и поменялось ведение экономики, промышленности, сельского хозяйства и иных человеческих действий. Современные информационные технологии и научные инструменты увеличили экономический потенциал страны, сделали разного рода работы легкими, задачи быстро решаемыми, увеличилась скорость обработки.

Современные информационные технологии оказывают всеобщее влияние на жизнь человека, делают его более сознательным, информированным и эрудированным. Современному человеку легче достичь поставленных целей.

Слово технология состоит из сочетания двух слов «техно и логика», «техно» означает мастерство, искусство и «логика» означает наука и обучение. Технология - это методы и инструменты предназначенные для облегчения решения проблем, с которыми сталкивается человек на своем жизненном пути.

В настоящее время социальное медиа пространство приблизило общество друг к другу, сократилось расстояние. Современные информационные технологии являются индикатором социальной революции общества, повысился уровень качества жизни общества, культурная осведомленность перешла на высокий уровень развития. Наука и техника оказывает большое влияние на образование и развитие общества. Как мы знаем образования, промышленность, экономика - это важные составляющие общества. Благодаря современным информационным технологиям человек начал осознавать за пределами воображения, ведь виртуальные технологии начали этому способствовать, благодаря погружения человека в воображаемый мир [1].

Наука и техника очень высоко влияют на трудовую деятельность общества, в отличие от прошлых столетий, 21 век стал веком прогресса в области современных информационных технологий, которые ускорили процесс работы в разных сферах деятельности общества. Современный человек начал больше зарабатывать за короткий период времени. Появились новые методы, которые очень позитивно играют на уровень жизни.

Технологическая революция охватила каждый аспект жизни: машины начали выполнят общественные функции вместо человека, и при том на высоком уровне точности и производительности. Очень много примеров технологий, которые облегчают решение любой социальной проблемы, с которым человек может столкнуться в процессе своей деятельности. Например, у человека появилась проблема в организме, сегодня благодаря современным компьютерным аппаратам можно определить любую болезнь, и своевременно оказать лечебную помощь. Все виды деятельности человека находятся под влиянием технологий: жилье, транспорт, работа, питание, досуг, искусство, воображение и в целом вся жизнь [2].

Наука и техника - это организованный поиск истины и объективного знания, потому что наука говорит нам о реальности в любом процессе. Благодаря технологиям можно выявлять опасные для человека стороны его деятельности. Технологии играют важную роль на нашу общественную жизнь. Технологии помогают нам использовать правильно современные навыки, умения и знания в техническом прогрессе. Мы сталкиваемся технологиями каждый день, даже дома: ТВ, радио, компьютер, стиральные машины, микроволновые печи, поезда, автомобили, самолеты, смартфоны, обычные телефоны и тому подобное. Итак, наша общественная жизнь полностью зависит от науки и техники.

Обзор отечественной и зарубежной литературы.

Иорданский ученный Аль-Маджали в своем научном исследовании «Влияние использования интернета на социальные отношения между студентами в Иорданском обществе». Он для исследования привлек 325 добровольцев из Мутахского университета. Проведенное исследование показало, что благодаря Интернету возросли социальные отношения, студенты стали ближе друг к другу, они слишком много времени проводят в Интернет пространстве. И еще исследование показало, что Интернет-технологии широко используются в пределах учебных кампусов [5].

Арабский ученный ЛайлаАрихскаяв своем научном труде «РольСМИ и ИТ в разрушении семьи: мониторинг состояния семьи и детей». Она провела исследование и выявила негатив- 
ность СМИ и Интернета в семье. В данном исследовании были выявлены ряд проблем, который вызывает современный мир информационных технологий. Семьи рушатся, дети остаются разлученными с одним из родителей. Теряются ценности семьи, некоторые покидают семьи поддаваясь слабостям, которые выявляет у них Интернет. Для пользования Интернетом человек должен иметь здоровую позицию, и уметь правильно все анализировать, и вся суть технологий заключается в этом. Современные технологии подавляют идентичность личности у некоторых слабых психически людей [2].

Иорданский ученный Аль-Юсуф провел исследование на тему «Достоинства и недостатки современных технологий». Он в этом исследовании выявил вред чрезмерного нахождения в виртуальном пространстве. В ходе исследования было установлено, что чрезмерное использование Интернета приводят к следующим негативным последствиям: небрежность, потеря самоконтроля, потеря чувства времени и уклонение от реальных отношений. В общем вся жизнь находится под ударом, негатив начинает проявляться на каждом шаге. Данное исследование было направленно для выявления негативного фактора, и как бороться с ним. Если Интернет-пространство правильно использовать, то это большое благо для общества.

Научный сайт «Бартбли» вывесил у себя научную статья на тему «Влияние технологий на современное общество». Они в исследовании показывают, что современные информационные технологии имеют закономерность 50 на 50. То есть в ИТ много пользы, и в тоже время вредя. Конечно люди во всем мире получают пользу от современных информационных технологий [3].

На научном сайте «Люмен обучение» размещена научная статья «СМИ и технологии в обществе». В этой статье автор связывают СМИ и человека, как неотделимые друг от друга части. 21 век стал веком слияния человека и СМИ. Сегодня нельзя найти человека, который бы не интересовался СМИ и Интернетом. Человек с рождения привыкает к миру, где самая ценная вещь - это информация. За информацию можно что угодно купить и продать [4].

Эксперт по электронному бизнесуДхрувилПателс рассматривает информационные технологии, как подмножество информационно-коммуникационных технологий (ИКТ). Он выявил, что очень трудно выявить конкретную технологию, которая бы преобладала над всеми другими, потому что технологии для разных направлений используются разные [1].

Инсарова А. и Корпачева П. в своем исследовании «Теоретический анализ влияния современных информационных технологий на трансформацию организационного пространства» анализируют влияние современных информационных технологий на изменение организационного пространства. Несмотря на развитие теоретико-методологических подходов и теоретических концепций по данной проблеме, процесс трансформации организационного пространства под воздействием информационно-технологического прогресса остается не до конца изученным в силу латентного воздействия технологизации на общество в целом и на организации в частности [5].

Методология исследования: это исследование в основном носит описательный и аналитический характер. В данном исследовании была предпринята попытка проанализировать развитие общества в условиях современных технологий. Данное исследование основано на данных различных научных статей. Для исследования были прослушаны Радио каналы, просмотрены передачи передач по ТВ. Это статья содержит ссылки на отечественную и зарубежную литературу.

В ходе исследования были выявлены следующие методологические задачи:

- знать о влиянии науки и техники на образование;

- знать о влиянии науки и техники на сельское хозяйство;

- знать влияние науки и техники на окружающую среду;

- знать о влиянии науки и техники на коммуникацию;

- знать о влиянии науки и техники на здоровье и гигиену;

- знать о влиянии науки и техники на инфраструктуру;

-знать влияние науки и техники на правительство и его планировании.

1. Влияние науки и техники на систему образования велико - это связано с тем, что современному миру нужны люди, которые будут уметь пользоваться современными компьютерными технологиями, чтобы выполнять свои обязанности. В системе образования технологии используются на постоянной основе, чтобы можно было черпать знания со всего информационного образовательного пространства. 
2. Влияние науки и техники на сельское хозяйство. Развитое сельское хозяйство - это гарант сытости граждан на определенной территории. Благодаря современным технологиям повысилась возможность воздействовать на все происходящие процессы в сельском хозяйстве. Благодаря технологиям можно контролировать весь процесс, происходящий в сельском хозяйстве.

3. Влияние науки и техники на окружающую среду. Техника и окружающая вреда взаимосвязаны, они научились находит компромиссы. Сегодня нельзя найти такую область, где не применяется наука и техника. Сегодня весь мир загрязняет окружающую среду. Ну в некоторых развитых странах используются технологии, в основе которых находятся заводы по переработке мусора и бытового отхода. Это очень важный шаг. На сегодня Индия лидирует по загрязнению окружающей среды.

4. Влияние науки и техники на коммуникацию. После появления Интернет-пространства расширились границы коммуникации общества. Сегодня каждый может отправить сообщение родным людям, границы уходят на второй план. Коммуникация является важной частью современной жизни, т. е. мир становится глобальной вселенной по мере развития науки и техники особенно у в информационной технологии. Наука и техника принесли просвещение в методах коммуникации нового времени. Для любого социального развития или социального контроля технология является стандартным ключом, чтобы принести революцию в социальной коммуникации.

5. Влияние науки и техники на здоровье и гигиену. В медицине для диагностики заболеваний используются различные технологии, которые дают преимущества для дальнейшейдиагностики. Многие ученные мира придумывают новые вакцины от заболеваний, создают современные больницы, где есть все для того, чтобы спасти человека. Использование Интернета дает очень много возможностей для человека умственного труда. Благодаря современным коммуникациям устанавливается тесная удаленная взаимосвязь.

6. Влияние науки и техники на инфраструктуру.

Инфраструктура является блоком развития в Азии. Современные технологии обеспечили основные средства для развития инфраструктуры. Развитые страны признаны солидной инфраструктурой, так что это необходимо для страны, чтобы стать современными в средствах инфраструктуры. Наша страна также движется в сторону больших изменений в виде инфраструктуры, и она имеет покрытие почти всех необходимых требований общества, такие как дороги, эстакады, мосты, больницы, учебные заведения, колонии, общественные парки, общественные туалеты, железная дорога, торговые центры, парковочные зоны и правильное расположение бытового мусора, национальные парки, для общественного благосостояния. Технологии играют важную роль в становлении общества. Где продвинутые технологии там продвинутое общество.

7. Влияние науки и техники на государственное управление. Сегодня нельзя представить государственный аппарат без использования компьютерных технологий. Так как технологии являются важным составляющим в процессе управления государством. Сегодня на нашей земле нет Правительства, которое бы не использовало Интернет-технологии в государственном секторе управления. Ведь обмениваться с информацией в разных структурах легче с помощью Интернет-технологий. Они стирают границы между странами, государственными организациями.

Вывод: данная статья показывает развитие общества в условиях современной технологической революции, которая охватила все области деятельности общества. Наука и техника приносить пользу практически во всех направлениях. Ведь человеку свойственно допускать ошибки, а технологии не допускают их, что является важной положительной стороной. Технологии повышают качество и надежность. Создают условия для динамики развития общественных взаимоотношений. Сегодня все отрасли науки охвачены технологиями. Даже дети с рождения подвержены к слиянию с миром технологий, которые облегчают процесс сосуществования с природой. Человек научился жить в мире с природой и техникой, когда нарушается дисбаланс, то начинаются войны, распри, нарушается общая целостность мира. Для сохранения стабильности в мире создаются разные советы по общим мировым вопросам, что очень важно в условиях информационного общества, которое является главным звеном в современном мире. Многие ученные едины во мнении, что все технологии несут с собой благо, и в тоже время зло. Главное научиться жить в гармонии с природой. 
Нарушение гармонии и целостности с природой приводят человечеству в упадок, нельзя этого допустить. И для этого необходимо усилить институты семьи и детей. Такого мнения придерживаются многие социологи и психологи. Сегодня нельзя представить себе ситуацию, к которой нельзя было бы найти решение. Так как любая задача имеет решение, только необходимо научится использовать необходимые методики. Современный информационный мир, где технологии играют основную роль, ими диктуются правила игры, которые необходимо соблюдать [6].

Разные специалисты следят за тем, какую пользу приносят обществу наука и техника. Технологии влияют на поведение общества. Технологии влияют на процесс взаимодействия на каждом шагу. Технология наполнила нас бесценными дарами, которые были выше человеческого воображения. Технологи сделала чудеса в каждой области, будь то образование, сельскоехозяйство, связь, здравоохранение и гигиена, транспорт, окружающая среда, инфраструктура и управление. Это принесло революцию в социальный процесс и сделал нашу жизнь связанной с каждой частью глобального мира. Наука сделала инновации, которые проверяют необходимые требования к здоровью человека и социальной среде обитания. Наши ресурсы вода, почва, воздух, леса жизнь предотвращена от любого загрязнения современными технологиями. Наше общество испытывает на себе технологическую революцию, когда основную роль играют технологии. Человечество не сможет изменить будущее, ну оно может его сделать удобнее и приятнее. Все эти революционные шаги в области техники и науки оказывают положительное влияние на наше сообщество. Технология сделала рабочий процесс настолько быстрым, и каждое действие обрабатывается в короткий период времени. Это приводит к экономии времени и денег, что является большим достижением для людей, живущих в обществе. Развитые страны управляют каждой вещью на технологиях, поэтому становятся все более и более развитыми. Наша страна быстро движется в направлении развития, но оно все еще требует много шагов в каждом аспекте технического поля и других участков услуг по развитию страны. Для того чтобы сохранить социальную среду люди должны использовать современную технологию согласно основным принципам правительства и должны взять на себя ответственность в формирования общественного мнения.

Развитие общества в условиях технологической революции на прямую зависит от трезвости подхода и взвешенности действий. Мы не можем изменить общий механизм природы, ну мы можем использовать его с пользой для себя.

Технологическая революция назревала веками, только в наше время нашла все возможные решения для бурного развития. К этому человечество шло несколько тысяч лет. Сегодня нельзя удивить человека новой технологией - это осадок технологической революции. Сегодня важно понимать, что общество испытывает пик насыщения информационными потоками со всех сторон, главное правильно анализировать и впитывать в себя все происходящее.

\section{Список использованной литературы}

1. Данакин Н.С., Конев И.В., Хазиев И.Х., Строкова В.В., Муртазаев С.А., Алисултанова Э.Д., Щербакова А.И. Качество профессионального образования в контексте обеспечения национальной безопасности/Научная монография//Белгород, 2015.156с.

2. Развитие общества в условиях современной технологии. [Электронный ресурс]// режим доступа: https://www.researchgate.net/publ ication/324654099_Development_of_Society_ under_the_Modern_Technology_-_A_Review (дата обращения 05.05.2021г.)

3. Влияние технологий на современное общество. [Электронный ресурс]// режим доступа: https://www.bartleby.com/essay/Effect-of-Technology-on-Modern-Society-F3J8GJUSTJ (дата обращения 06.05.2021г.)

4. СМИ и технологии в обществе. [Электронный ресурс]// режим доступа: https://courses.lumenlearning.com/sociology/chapter/media-and-technol ogy-in-society/ (дата обращения 07.05.2021г.)

5. Теоретический анализ влияния современных информационных технологий на трансформацию организационного пространства. [Электронный ресурс]// режим доступа: https://cyberleninka.ru/article/n/teoreticheskiy-analiz-vliyaniya-sovremennyh-informatsionnyhtehnologiy-na-transformatsiyu-organizatsionnogo-prostranstva (дата обращения 08.05.2021г.)

6. Что такое современные информационные технологии? [Электронный ресурс]// режим доступа: https://www.quora.com/What-is-modern-information-technology (дата обращения 09.05.2021г.) 